\title{
¿ORIENTE ES ORIENTE? FEMINISMO E ISLAMISMO EN MARRUECOS*
}

\author{
ÁNGELES RAMÍREZ FERNÁNDEZ
}

Universidad Autónoma de Madrid

\author{
PALABRAS CLAVE ADICIONALES \\ Movimientos de mujeres, Modelos de género, \\ Asociaciones islamistas, Cambios jurídicos.
}

\author{
ADDITIONAL KEYWORDS \\ Women's Movements, Gender Model, Islamist \\ Associations, Juridical Changement.
}

RESUMEN. El presente artículo analiza los movimientos de mujeres en Marruecos, confrontándolos a lo que viene siendo el esquema habitual de tratamiento: movimientos feministas, de tipo occidental, frente a movimientos islamistas, más "auténticos", pero de carácter represivo. A través de un análisis de los cambios jurídicos en Marruecos, así como de los modelos de "mujer" que defiende cada movimiento, el artículo muestra que el esquema explicativo de la dicotomía de islamismo frente a feminismo para explicar la cuestión no es válido. Su uso no es neutro, y en ocasiones puede tener consecuencias perversas, que primitivizan al "otro". En cambio, el estudio de estos movimientos en el contexto social y político marroquí, puede arrojar luz sobre un problema que estimula, en ocasiones, y bloquea, en otras, el cambio en Marruecos.

ABSTRACT. This article discusses some women's movements in Morocco. It intends to demonstrate that the usual model that is used to explain women's movements in the Arab World is not valid. This model considers two kinds of women's movements: on the one hand, Western feminist movements, occidentalists, and on the other, Islamist movements, which are theoretically more authentic but also more repressive. Through the analysis of the positions adopted by Islamist and Feminist groups toward juridical changes of Mudawana, as well as the constructions of "womanhood" in these groups, the article shows how this dichotomous model oversimplifies the explanation of these processes. Furthermore, the use of this model in the research is not neutral. It has political consequences, such as the primitivization of the other. Ethnography makes possible other approaches to the topic and allows us to build a more nuanced interpretation.

* He elegido este título para el artículo por la Balada de Oriente y Occidente (Ballad of East and West), de Rudyard Kipling, escrita en 1889. En ella, hay una frase "Oh, Eastis East, and West is West, and never the twain shall meet" (Oriente es Oriente, $y$ Occidente es Occidente, y nunca se encontrarán), cuya primera parte ha sido de las más citadas, aunque de polémica interpretación, por lo polémico del personaje y sus relaciones con el imperialismo británico en la India. En todo caso, la cita ha sido y es profusamente usada para señalar la profunda separación entre los dos mundos.

E-mail: aramirez@Princeton.EDU

\section{Revista Internacional de Sociología (RIS)}

Tercera Época, No 39, Septiembre-Diciembre, 2004, pp. 9-33. 
RIS

REVISTA INTERNaCional DE SOCIOLgGta

No 39, SEPTIEMBRE-DICIEMBRE, 2004

ÁNGELES RAMÍREZ FERNÁNDEZ

\section{INTRODUCCIÓN}

Este trabajo se inserta en una trayectoria que viene teniendo como uno de los puntos clave la relación entre género e Islam. Una primera y extensa investigación consistió en identificar la inmigración de las mujeres marroquíes como factor de empoderamiento (empowerment), y éste se producía en la medida en que había un alejamiento de lo que era percibido como "musulmán". En este sentido, el proceso apuntalaba, con matices, lo que ha sido el esquema básico del feminismo dominante en Europa y en Estados Unidos: la lucha por la emancipación femenina indisolublemente vinculada al acceso a recursos propios, al abandono del hogar y de los papeles tradicionales y a la movilidad espacial. Y sin embargo, a la vez que eso sucedía en los primerísimos años 90 en España y Marruecos (los dos países de referencia) tenía lugar una construcción del Islam como un movimiento de resistencia de género, que comenzaba a encontrar eco en la bibliografía y que venía firmado por nombres iraníes'. Esta construcción se efectuaba en torno a movimientos que ya existían previamente y que paradójicamente se habían considerado, desde fuera y desde dentro de sus países, portadores de un modelo tradicional y represor para las mujeres, dentro de la sociedad que preconizaban. Estos eran los movimientos islamistas. ¿Cómo conciliar entonces la idea de movimientos emancipadores dentro de modelos represivos? ¿Qué sostenían exactamente estas mujeres? ¿Por qué el Islam parecía ser en ocasiones un obstáculo al empoderamiento y, en otras, un acicate? ¿En qué condiciones se producía una y otra situación? Esta necesidad de indagar hizo que me planteara esta investigación, que engarzaba con la que he mencionado en primer lugar ${ }^{2}$.

La situación de las mujeres en el mundo arabo-musulmán es uno de los temas fundamentales en los procesos de democratización en el área, aunque no sea de los más analizados en la literatura científica, o al menos, no desde esta perspectiva.

\footnotetext{
${ }^{1}$ No son las feministas y académicas iraníes las primeras en hablar del tema, pero sí lo son en debatirlo y en ponerlo al nivel de la discusión de otros feminismos llamados étnicos. Agradezco a mis evaluadores anónimos sus comentarios en este sentido.

${ }^{2} \mathrm{Y}$ también el método de investigación fue continuista. Si para la investigación sobre inmigración, realicé trabajo de campo en España y en Marruecos a lo largo de siete años, con diferentes grupos familiares de mujeres, llevando a cabo observación participante, ésta la he planteado, como corresponde a la disciplina en la que me inscribo, la antropología social, de la misma manera. Comencé mi trabajo de campo a principios de 2003, y éste se ha compuesto de varias estancias de tres a cuatro semanas en Marruecos, que he aprovechado para hacer observación participante con mujeres implicadas en grupos religiosos, así como para realizar entrevistas a responsables feministas e islamistas. Gracias a una tupida red de contactos que se empezó a tejer al principio de mi trabajo en Marnuecos, en 1990, he podido disponer de un observatorio particularmente interesante: el que me ha proporcionado un grupo de familias residentes en un barrio popular de una de las grandes ciudades marroquíes. Asimismo, he realizado entrevistas y observación entre los islamistas de la inmigración en Europa, por entender que el proceso no es comprensible sin esta dimensión transnacional.
} 
La "cuestión de las mujeres" no suele tratarse considerando que la igualdad sexual sea un requisito para la democracia, sino en sí misma y de forma separada de otras cuestiones. De hecho, el marco desde el que se trata la cuestión de las mujeres es el cultural o el religioso-cultural, en el caso de los países arabo-musulmanes. Este tipo de análisis responde a una construcción colonial, como sostiene Ahmed (1992), y en muchos sentidos, permea aún una buena parte de la investigación.

En los últimos tiempos, la bibliografia presenta un mundo arabo-musulmán dividido entre un feminismo de tipo occidental y un islamismo con un proyecto femenino que reprime a las mujeres. Eśta división entre movimientos seculares (feministas) y movimientos de mujeres islamistas (religiosos), es arropada por el feminismo transnacional ${ }^{3}$, que apoya con recursos al primero y que renuncia de entrada a conocer el segundo ${ }^{4}$. Esta actitud del feminismo transnacional se debe a que considera que las reivindicaciones de los islamistas con respecto a las mujeres contradicen el esquema básico del feminismo en Europa y Estados Unidos: la negación de la diferencia entre hombres y mujeres. El apoyo internacional al feminismo de los países arabo-musulmanes refuerza la polarización entre feminismo e islamismo, y termina siendo imposible cualquier forma de trabajo conjunta, por más que haya simpatizantes de esta idea entre las militantes de ambos bandos. El esquema de la polarización puede ser válido para algunos contextos nacionales, pero no es una explicación independiente de las circunstancias, y no es válida para todo el área. Cabe decir que, si bien denostados por muchos movimientos de izquierda, existe en Europa la idea de que "lo auténtico" de los países arabo-musulmanes son los movimientos de tipo islámico e islamista, y lo otro es importado, y no se adapta a la "cultura propia". Este argumento es la base de perspectivas opuestas, que sobrevaloran o infravaloran lo arabo-islámico. En el marco del tema que nos ocupa, esta línea se traduce en dos posturas contrapuestas: por un lado, la consideración de los movimientos feministas como ilegítimos y la sobrevaloración de todo lo islámico como auténtico y, por otro lado, o más bien, desde el otro lado, la idea de que la "cultura" arabo-musulmana sólo puede dar lugar a movimientos retrógrados, contrarios a los valores de la Ilustración, y que tienen en el velo y en el terrorismo la manifestación de su esencia.

En este artículo se pretende mostrar que, para el caso de Marruecos, el panorama asociativo femenino no se resuelve con este esquema que presenta un feminismo de tipo secular y un movimiento anti-feminista de tipo musulmán,

\footnotetext{
${ }^{3}$ Con la toma del poder por parte de los talibanes en Afganistán, se consolida una nueva fase de lo que se puede llamar feminismo transnacional. Los movimientos feministas europeos y sobre todo el norteamericano, se lanzan a la "salvación" de las mujeres afganas (Moghadam, 2001).

${ }^{4}$ Cuando sale la cuestión islamista en entrevistas con políticos extranjeros o representantes de la cooperación o de organismos internacionales que residen en Marruecos o que tienen cierta relación con este país, la reacción es bastante negativa. Desde el punto de vista social, el islamismo se considera en muchos casos un fascismo.
} 
que reivindica un papel tradicional para las mujeres. En Marruecos hay diferentes movimientos de mujeres, y una parte importante de estos movimientos están vinculados al islamismo. La cuestión que se plantea en este artículo es la siguiente: los movimientos de mujeres que son de inspiración islámica y que plantean proyectos específicos para las mujeres, ¿pueden ser considerados como una especie de feminismo islamista? ¿Es posible hablar de feminismo dentro de un marco islámico? Se propone, para resolver esta cuestión, una pequeña discusión metodológica sobre la relación entre feminismo e imperialismo. Me centro después en el análisis de la "cuestión femenina" en Marruecos desde el punto de vista jurídico y de las reacciones de los diferentes grupos respecto a este tema. Continúo con el análisis, algo más amplio que el jurídico, de los "modelos de mujer" que sostienen islamistas y feministas en Marruecos. Termino este recorrido volviendo a plantear la pregunta de partida. Para contestar a la pregunta sobre el feminismo islamista, este artículo indaga en los movimientos islamistas marroquíes. Haré referencia a los movimientos feministas, que son parte fundamental de mi investigación, pero cuya descripción no es objeto de este trabajo. Los movimientos feministas marroquíes, exceptuando las referencias al Islam, que más tarde aclaro, siguen de cerca los movimientos feministas europeos de tipo universalista, y las demandas no son diferentes de las de éstos. Sus militantes se consideran a sí mismas feministas y mantienen una tupida red de contactos con el feminismo transnacional.

\section{CUESTIONES METODOLÓGICAS A PROPÓSITO DEL FEMINISMO COLONIAL}

La defensa de una u otra posición: si hay feminismo islamista o si no lo hay, no es neutral. La cuestión de las mujeres ha sido utilizada políticamente en el mundo arabo-musulmán para justificar diferentes situaciones de dominación por parte de poderes internos y de fuerzas externas. Una de las más interesantes es que esta asociación entre Islam y mujeres, que comienza a hacerse en los discursos políticos y académicos de Europa y Estados Unidos, ha contagiado a los propios países arabo-musulmanes, y tiene una incidencia en la política interna, como sucede en el caso de Marruecos. Aún hoy, y en diferentes medidas según los países, la cuestión de la mujer es un tema político en todo el mundo arabo-musulmán, y lo es especialmente en el Magreb (Daoud, 1992).

¿Por qué existe esa asociación entre el Islam y las mujeres en el discurso europeo y norteamericano sobre el mundọ arabo-musulmán?

Las teorías sobre el proceso evolutivo de las razas situaban a los poderes coloniales del XIX en la etapa superior de desarrollo. Esta posición era sancionada por los datos que los misioneros, entre otros, recogían sobre el terreno, y que fueron conformando las bases de la moderna antropología. Para Ahmed (1992), 
esta antropología servía para un doble fin: para el proyecto colonial británico, legitimando la dominación, y para otro proyecto, este interno, apuntalando el orden androcéntrico. Y es que esos datos reforzaban el rol doméstico de las mujeres, a la vez que confirmaban su inferioridad. Pero aún había otra vuelta más de tuerca. El poder victoriano, que obviamente no comulgaba con las reivindicaciones feministas, usaba sin embargo este discurso feminista para redirigirlo contra las culturas dominadas, es decir, contra los "otros" hombres, los varones de las "otras" culturas, según Ahmed (op. cit.). Y este feminismo colonial es el origen de esta fusión entre la cuestión de las mujeres, de su opresión y de las culturas de otros hombres. No hay que perder de vista el hecho de que, en el momento en el que se conforma este discurso, la situación de las mujeres dentro de las metrópolis no es muy diferente a la de las naciones colonizadas, y que los mismos representantes del poder colonial británico que luchaban contra el velo en Egipto, por considerarlo un signo de la opresión de las mujeres, formaban parte activa de Ligas contra el voto femenino en Inglaterra, según relata Ahmed. En el caso del colonialismo español en Marruecos, hay también alguna muestra de esta cuestión. Un estudioso del Marruecos del siglo XIX, donde ejerce como médico, Felipe Ovilo, sostiene que la situación de las mujeres es consecuencia del atraso del país, y escribe un texto sobre ello ${ }^{5}$. También, y según relata Mateo Dieste (2002), los informes de los interventores del Protectorado marroquí, se referían a la posición inferior de la mujer en Marruecos como indicador "natural" del retraso de Marruecos ${ }^{6}$. Es bien conocido que, como consecuencia de esta presión colonial, las sociedades colonizadas reaccionan, y el pensamiento renovador, en el caso de algunos países como Marruecos, se desliza (Daoud, op.cit.) hacia un conservadurismo que sin duda marcará también la historia del feminismo marroquí, como la de otros movimientos sociales.

En definitiva, esto da forma a un discurso, ampliamente compartido, que sostiene que la causa del retraso secular de las sociedades arabo-musulmanas es la situación de opresión de las mujeres. Además, la consideración de la opresión sin más justificaba (justifica) las intervenciones e injerencias de diversos tipos en los países donde las mujeres están en esta situación. Como ejemplo ya clásico, el ataque a Afganistán por parte de Estados Unidos?

\footnotetext{
${ }^{5}$ Ver a este respecto, Ovilo (1881); un estudio sobre el tema puede encontrarse en López y Ramirez (2002).

${ }^{6} \mathrm{El}$ análisis de estos comentarios ha de hacerse desde la consideración de que los interventores en cuestión venían de la España de los años cuarenta, donde la posición de las mujeres españolas desde el punto de vista jurídico, social y político no difería en lo esencial de la de sus coetáneas marroquíes.

${ }^{7}$ Abu-Lughod (2002) se refiere a un discurso de la esposa del presidente Bush Jr. con respecto al ataque de Afganistán por parte de Estados Unidos, y cómo termina diciendo que, gracias al ataque, las mujeres saldrán de sus casas, enseñarán a sus hijas sin miedo a ser castigadas, y que la lucha contra el terrorismo es también la lucha por los derechos y por la dignidad de las mujeres.
} 
Con este discurso condenatorio de ciertas prácticas u organizaciones, como el uso del velo o la movilización islamista de las mujeres, y con esta focalización de lo característico de las culturas en estas prácticas, estamos, como se hizo en esa época del "feminismo colonial", favoreciendo la reproducción de esta consideración de las culturas no occidentales como primitivas, como relata Lindisfarne (2003), refiriéndose al imperialismo americano. En este sentido, no se entra siquiera en la posibilidad de que los movimientos islamistas puedan estar ofreciendo a las mujeres una forma de agencia ${ }^{8}$, y que sean algo más que un sistema de obligaciones sobre la vestimenta y que atenta contra los derechos humanos ${ }^{9}$. Pero a veces, el interés por no hacer el juego a aquel discurso desvalorizador y primitivizador de otras culturas puede llevar a todo lo contrario, a apoyar opciones que reivindican el valor intrínseco de esas prácticas sólo por el hecho de que, en estos discursos, son asociadas a símbolos identitarios, en un juego de relativismo cultural ${ }^{10}$. Es esta perspectiva la que convierte a los movimientos de mujeres dentro de los grupos islamistas en la única forma de feminismo legítima en los países musulmanes, porque considera las otras opciones (como el feminismo clásico) como culturalmente poco o menos auténticas. En este artículo, voy a plantearme la pregunta acerca del feminismo islamista, y lo voy a hacer a partir de dos cuestiones clave: en primer lugar, la generación y performance de los diferentes movimientos que presentan reivindicaciones de género, y en segundo lugar, los modelos de "mujer" que sostiene cada uno de ellos.

\section{FEMINISTAS E ISLAMISTAS MARROQUÍES}

Los datos sobre historia del feminismo y del islamismo en Marruecos permiten reconstruir la historia sociopolítica del país. El feminismo marroquí surge de los sectores de mujeres de los partidos políticos en su práctica totalidad. Esta circunstancia ha provocado que haya habido una gran dependencia de los movimientos feministas con respecto a los partidos-madre. Y ello a veces es ha sido esgrimido contra los movimientos feministas, sobre todo por parte de ciertos islamistas, que destacaban así la poca credibilidad de los movimientos feminis-

\footnotetext{
${ }^{8}$ El estudio de ciertos temas, como velo o ablación, por ejemplo, tal y como se proponía la antropología en sus comienzos, aplicando la versión metodológica del relativismo cultural, puede conducir a que, desde la comunidad científica, eso sea interpretado como una connivencia con esas prácticas. Y redunda en la evitación, por parte de los investigadores, de ciertos temas. Podría compararse a lo que ocurre cuando se trabaja sobre cuestiones de terrorismo.

${ }^{9}$ Discurso presente en textos como el de Elorza (2002) o, en otro nivel, los de Massana (2004) "La revolución silenciosa", EL PAIS, 1.2.2004 y Antonio Elorza, "Yihad en Madrid", EL PAIS, 18 de marzo de 2004.

${ }^{10}$ Es el caso de Martín Muñoz (2002) "Multiculturalismo e islamofobia", EL PAIS, 1.02.2003.
} 
tas, ya que procedían de instancias tan poco recomendables como los partidos políticos marroquíes.

Las dos organizaciones principales de mujeres islamistas también surgen de otros movimientos políticos mayores que no son exclusivamente femeninos. La primera de ellas, la Organización para la Renovación de la Conciencia Femenina (en adelante, ORCOFE), procede del Partido de la Justicia y el Desarrollo (PJD); la segunda, Insaf, es una asociación formada por mujeres del movimiento de $A l$ Adl ua-l-Ihsán ${ }^{11}$ (en adelante, $\mathrm{YAI}^{12}$ ).

No deja de ser interesante el hecho de que las responsables de los movimientos femeninos, tanto los procedentes del ámbito secular (feminista) como religioso (islamista), cifren en igual circunstancia el nacimiento de las organizaciones que dirigen: la de que en su momento hubiera asuntos que serían mejor tratados por "sectores" de mujeres que por el partido o el movimiento en general. Y esto supone dos cosas importantes: la primera, que tanto los partidos islamistas como los considerados de la izquierda, no toman la cuestión de las mujeres como prioritaria en su proyecto político, y que, ante esta situación, la estrategia política de las militantes es idéntica; la segunda, que feministas e islamistas, con algunas excepciones, hacen un diagnóstico parecido en lo que se refiere a la situación de las mujeres, y hasta cierto punto, utilizan estrategias que tienen como base la formación y la educación. Los dos tipos de movimientos, en tanto que movimientos de mujeres, pueden calificarse de modernos, ya que la propia cualificación de movimientos de mujeres lo es (Molyneux, 2003). Y esto, a pesar de un discurso, por parte de los grupos islamistas, que plantea una vuelta al pasado, una reconstrucción de una sociedad antigua, correspondiente a los primeros tiempos del Islam. Esta recreación constituye la base de la legitimación de estos movimientos, que juegan justamente con la deslegitimación de los que no se apoyan en ella. Pero no son los únicos en este sentido. Incluso los movimientos feministas recurren al Islam como forma de estar en el mundo. Las feministas marroquíes apuntan al Islam como su marco cultural propio. $Y$ esto les distingue de otros movimientos feministas magrebíes y del resto del mundo arabo-musulmán, que apuestan por una estrategia de secularización. Esta idea encuentra eco en Darif ${ }^{13}$, que habla del "référentiel islamique" de las feministas de Marruecos. En mi opinión, sin

\footnotetext{
${ }^{11}$ Normalmente, cuando los especialistas se refieren al PJD, lo hacen por las siglas del nombre en francés o español, nunca por el nombre en árabe, que es $A l$ Adl ua al Tanmia, mientras que para el Adl ua-l-Ihsán, suele preferirse el nombre en árabe, a veces acortado como el $A d$. Durante mucho tiempo, se ha traducido del árabe como Movimiento de Justicia y Caridad, pero los propios líderes han protestado por esta traducción, y han insistido en la que ahora se maneja, Justicia y Espiritualidad, ya que, para ellos, la espiritualidad es la esencia del movimiento, según Khalifi (2003) y Nadia Yassine (comunicación verbal, enero de 2004)

${ }^{12}$ Por Yemáa (Asociación) Al Adl ua-l-Ihsán.

${ }^{13}$ Mohamed Darif, entrevista. Casablanca, octubre de 2003.
} 
RIS

REVISTA INTERNACIONAL DE SOCIOLOGIA

No 39, SEPTIEMBRE-DICIEMBRE, 2004

ÁNGELES RAMÍREZ FERNÁNDEZ

embargo, este recurso al Islam forma parte de una estrategia nuevamente de legitimación ideológica por parte de las feministas, en un país donde el Islam y todo lo que teóricamente conlleva, constituye el patrimonio nacional, la Thurat, y no considerarlo es una traición y una herejía ${ }^{14}$.

El caso es que ha habido, desde hace unos años, un proceso de autonomización de estos movimientos femeninos con respecto a sus movimientos matrices, aunque la adscripción partidaria sigue siendo clara. En este sentido, los movimientos feministas que aún hoy están más identificados con formaciones políticas son los que colaboran más con el Estado, aunque conserven cierto grado de autonomía. En el caso de las asociaciones feministas, son las más independientes de los partidos políticos, como la Ligue pour la Défense des Droits des Femmes, o la Union d'Action Féminine las que más claramente se desmarcan de las acciones estatales y rehúsan cooperar con el Estado ${ }^{15}$. Respecto a las asociaciones islamistas, ninguna de las dos que aquí se estudian está autonomizada de los partidos o movimientos a los que pertenecen, aunque la tendencia parece ser ésa. La ORCOFE depende de un partido, el PJD, que está integrado en el sistema político marroquí, y no es así para el caso de Insaf, que pertenece a un movimiento anti-sistema, la YAI. La autonomía con respecto a otros grupos suele considerarse un requisito fundamental para evaluar si un grupo de mujeres es o no un movimiento de mujeres (Molyneux, 2003).

El PJD es un partido islamista, que aúna varias tendencias y que está presente en el Parlamento: es el llamado, por el Estado y por la prensa nacional e internacional, islamismo moderado. Ello es porque, a diferencia de $A l$ Adl ua-l-Ihsán, conocidos como radicales, el PJD acepta el juego político marroquí. En su proyecto político no tiene lugar el planteamiento de una sociedad musulmana, aunque sean guardianes vigilantes del Islam en la que hay. En esta aceptación de las reglas del sistema son, sin embargo, especialmente combativos con un tema: la cuestión de las mujeres. El PJD concurre a las elecciones desde 1997. En 2002 y 2003 se les forzó a recortar su representación (Hernández Ramos, 2003). En el 2003, sólo se presentaron en el $18 \%$ de las circunscripciones electorales. Sin embargo, en las circunscripciones de las grandes ciudades a las que se presentó, fue la primera o la segunda fuerza más votada. En Casablanca, Fez o Salé es la tercera fuerza en número de concejales, siendo la primera en Mequínez, Uxda, Tetuán o Safi (López y Moré, 2004).

\footnotetext{
${ }^{14} \mathrm{Si}$ las organizaciones feministas marroquies sostuvieran en su programa una secularización abierta de la sociedad, serían consideradas menos "marroquies" y culturalmente menos auténticas que las organizaciones religiosas, por ejemplo, lo cual deja a las primeras en una posición muy vulnerable en tanto que Occidente es acusado de muchos males en Marruecos.

${ }^{15}$ Entrevista con una responsable feminista y ex presidenta del Centro Fama para mujeres víctimas de violencia. Casablanca, octubre de 2003.
} 
La Organización para la Renovación de la Conciencia Femenina, o movimiento de mujeres dentro del partido, es formalmente, una asociación independiente que se forma en 1997. Sin embargo, su presidenta pertenece al PJD y es parlamentaria por este partido, y los miembros de la ORCOFE son militantes del PJD. La Organización y el partido comparten un mismo discurso con respecto a las mujeres. En general, no proponen grandes cambios con respecto a lo que hay, sino que, según Del Olmo (2000), pretenden estimular una nueva conciencia femenina, por medio de la revisión de los documentos jurídicos, con el objetivo de "preservar la identidad de nuestra sociedad y la dignidad de sus miembros" (op. cit: 53). Es importante añadir que este partido no tiene grandes diferencias con el partido nacionalista marroquí Istiqlal en cuanto a los planteamientos con respecto a las mujeres, aunque la forma de actuar contra el movimiento feminista, por ejemplo, haya sido mucho más virulenta (Tozy, 1999).

El otro movimiento islamista importante en Marruecos es el Adl ua-l-Ihsấn o YAI. Éste nace en 1982, según sus militantes. Ésta es, sin embargo, la fecha en que se depositó la solicitud para convertirse en asociación. Pero no fue admitida a trámite ${ }^{16}$ : ni son ilegales ni su existencia como asociación está regularizada. Esta condición de irregularidad, sin embargo, es capitalizada políticamente por la organización, que ve reforzado así su rasgo fundamental: de oposición frontal al régimen, del cuál no sólo no acepta participar en el juego político, sino que pone en cuestión el factor más importante de legitimación de éste, que es el carácter sagrado de la monarquía. Dicho de otra manera, la YAI no acepta que el Rey de Marruecos sea el jefe religioso del país y cuestiona la legitimidad de su poder, ya que no está sancionado por la comunidad musulmana. Puesto que no se presentan a elecciones, no hay datos sobre su volumen de militantes o simpatizantes. Según la propia organización, llegan hasta los dos millones de militantes. Los responsables de la YAI aseguran que conocen perfectamente el número de militantes, que distinguen del de simpatizantes, dada la compleja estructura de la organización. En definitiva, la YAI está fuera del sistema, pero lleva a cabo algunas acciones con el PJD, del que no acepta, sin embargo, su connivencia con el régimen, ni su proyecto social más o menos continuísta ${ }^{17}$. Respecto a la cuestión de las mujeres, ésta se encuentra presente en el proyecto político de la YAI de dos maneras. En primer lugar, por medio de la existencia de un sector de mujeres, que junto con el sindical y el de juventud, constituye el esquema organizativo que se superpone

\footnotetext{
${ }^{16}$ En realidad, en Marruecos, para que una asociación sea legalizada, basta con conservar el resguardo que certifica que se solicitó esa legalización. Abdesalam Yassine, el líder de $A l$ Adl ua-lIhsán, depositó la demanda en 1982, pero fue requerida tiempo después su presencia, según relata Tozy (1999) y se le conminó a entregar otra vez al Ministerio el resguardo de solicitud, con lo cual, a efectos legales, la asociación no existe.

${ }^{17}$ Entrevistas con militantes destacados (Abril, 2002 y Octubre, 2003).
} 
RIS

REVISTA INTERNaCIONAL DE SOCIOLOGLA

NN 39, SEPTIEMBRE-DICIEMBRE, 2004

ÁNGELES RAMÍREZ FERNÁNDEZ

al geográfico. En segundo lugar, por la creación de la Insaf en 1999, movimiento específico de mujeres dentro de la organización. El proyecto de la YAI pasa por la instauración, por medio de la educación, de una sociedad musulmana en Marruecos, y en este sentido, la reforma del estatuto de la mujer y de la familia se considera como un punto fundamental.

\section{LAS ASOCIACIONES A EXAMEN}

Una vez descrita la creación de estos movimientos, es interesante indagar en sus reivindicaciones para las mujeres. Esto lo voy a analizar a partir de la posición que los diferentes movimientos han tomado en dos momentos importantes de cambio para el estatuto de las mujeres: el Plan de Integración de las mujeres en el Desarrollo, en 1999, y el cambio en la Mudawana de 2003.

En Marruecos ha habido un antes y un después de los movimientos femeninos, y ese momento se sitúa en 1999. Es a principios de este año que la Secretaría de Estado encargada de la Protección Social, la Familia y la Infancia, y dirigida por Saad Saadi, antiguo comunista, elabora el Plan para la Integración de las Mujeres en el Desarrollo, siendo Primer Ministro el socialista Youssoufi, en el primer gobierno llamado de la alternancia, con Hasán II aún vivo.

El Plan es uno de los resultados de la aplicación de la llamada Plataforma para la Acción, documento elaborado según las directivas de la Cumbre de Pekín sobre las mujeres, en 1995, y resultado también de la acción de las feministas marroquíes, para las que la reivindicación del cambio jurídico ha sido un objetivo prioritario. Este documento prevé la incorporación de la perspectiva de género en el proceso de desarrollo sostenible. La equidad y el empoderamiento de los individuos son entendidos como requisitos de ese desarrollo. $\mathrm{Y}$ en Marruecos eso es algo que hay que estimular, puesto que una minoría que no lo es numéricamente, las mujeres, carece de los recursos sociales, políticos y jurídicos para lograr ese empoderamiento. Como en otras partes del mundo, el Banco Mundial ha estado presente en el proceso desde el principio, como co-organizador junto a las instituciones marroquíes y financiando una parte de los trabajos preparatorios, además de figurar como coautor en el propio texto. El Plan que se elabora, contempla, entre un amplio paquete de medidas educativas, sanitarias y laborales, una serie de cambios jurídicos que afectan a lo que, desde el punto de vista legal, es el único campo que aún tiene que ver con el Islam, el Código del Estatuto Personal o Mudawana. Es este código el que legisla el matrimonio, el divorcio, la filiación y la herencia, y el que establece la inferioridad jurídica de las mujeres con respecto a los hombres. Esta última parte del Plan es la que levanta más ampollas dentro del espectro político marroquí, y en definitiva, es la que termina enfrentando de manera más evidente, a las dos mitades de los actores políticos y sociales marroquíes, los "modernistas" y 
los "tradicionales"18. Las reformas jurídicas pretenden, entre otras cosas, retirar ciertos artículos que se consideran discriminatorios para las mujeres: se pretende prohibir la poligamia, acabar con la minoría de edad de la esposa frente al esposo, ya que la dirección del hogar corresponde al marido y la esposa es "tutelada" por éste, darle a las mujeres la facultad de contraer matrimonio sin necesidad de tutor, y hacer desaparecer el divorcio unilateral masculino, el llamado repudio. Todas estas figuras suelen ir conectadas con la tradición marroquí musulmana, ya que el Corán, fuente de derecho en este caso, las menciona. El hecho de que el Plan proponga su desaparición, es interpretado por sus opositores, los tradicionalistas, como un intento de acabar con la identidad marroquí y musulmana. Las asociaciones feministas, con otras asociaciones progresistas y con intelectuales destacados, forman la red de apoyo al Plan de Acción Nacional para la integración de las mujeres en el desarrollo (Réseau de Soutien au Plan d'Action National pour l'Intégration de la Femme au Développement). Los opositores, islamistas del PJD, políticos tradicionalistas y algún socialista, en contrapartida, se unen en la Liga Nacional para la Protección de la Familia Marroquí ${ }^{19}$. Hay que destacar que, a pesar de que el Adl ua-l-Ihsán se opone firmemente al Plan y aparece después apoyando al PJD en algunas acciones, no forma parte de esta Liga. Sí son parte de la Liga, sin embargo, señalados políticos socialistas.

Las críticas de la Liga al Plan van más allá de los cambios concretos. El Plan se considera, desde esta oposición, una prueba de la influencia de Occidente en los asuntos internos de Marruecos, y una amenaza a la familia marroquí. Sin embargo, y mientras que el manifiesto de la Liga hace hincapié en lo que podría suponer la aplicación del plan para los principios de la Ley islámica, que ha de regir la familia marroquí, la YAI centra más la crítica en los aspectos políticos y habla de imperialismo. La YAI ve el Plan como una prueba más de la capacidad de Occidente para intervenir en los asuntos propios de Marruecos, y a su vez, de la debilidad de los poderes marroquíes, que se venden de este modo. Para esta organización, el fin del Plan es controlar el crecimiento demográfico. Sostiene además, que es absurdo plantear este tipo de cambios como prioritario cuando las mujeres marroquíes tienen necesidades mucho más perentorias, que tienen que ver con la supervivencia. Esta diferencia entre los dos movimientos islamistas en

\footnotetext{
${ }^{18}$ Utilizo aquí el vocabulario que los marroquies comprometidos políticamente suelen emplear. El grupo de los modernistas coincide con las élites francófonas, cercanas a Europa, y que en este artículo está representado por las feministas. El grupo de tradicionales o tradicionalistas se corresponde con las élites arabófonas, musulmanas practicantes de modo más evidente que las otras, y que miran hacia los países árabes, aunque no puedan negar la cercanía con Europa.

${ }^{19}$ No hay que perder la vista el hecho de que el nombre de la organización formada para actuar en contra del Plan, esté en lengua árabe, y en esta lengua publiquen sus documentos, en medios de comunicación árabes.
} 
RIS

lo que se refiere al juicio sobre el Plan de Integración está vinculada al proyecto político de ambos, ya comentado más arriba.

Pero no puede decirse que el tono del Plan renuncie totalmente a la consideración del Islam. Se asegura en éste (Sécretariat d'Êtat, 1999) que las medidas propuestas en lo que se refiere al cambio jurídico están en función del referente religioso y son conformes al espíritu del texto coránico y a los fundamentos del Islam. Sin embargo, algunas líneas antes, hay una frase que sitúa este marco de referencia en otro lugar, y afirma que "los derechos de las mujeres son universales e inseparables de los derechos humanos", y se pregunta si es legítimo que la tradición jurídica islámica tenga un lugar en el seno del derecho de familia. Y si es así, continúa el texto: “¿Qué tradición islámica y qué lugar debe ocupar en el sistema social?" (pg. 74). En este sentido, puede decirse que, a pesar de las menciones al Islam, el texto del Plan rompe con toda una tradición de planteamiento del problema en términos islámicos y lo más interesante es que es un texto que surge del gobierno marroquí, por más que las organizaciones internacionales hayan estado ahí.

\section{EL GRAN CONSENSO}

Pero esta ruptura con el tono habitual que regía los proyectos de cambio jurídico en Marruecos iba a durar poco tiempo. Los desacuerdos en torno al Plan sembraron la disensión en el seno del propio gobierno marroquí, ya que el ministro de Asuntos Islámicos se pronunció públicamente en contra y se mostró dispuesto a impedir la puesta en marcha de las reformas. El problema encontró su eco público en las manifestaciones. de Casablanca y Rabat, del 12 de marzo de 2000. La de Casablanca, organizada por los detractores del Plan, y apoyada por la YAI, reunió entre 600.000 y 1.000 .000 de personas. La de Rabat, de la Red de Apoyo al Plan, concentró a un volumen de entre 60.000 y 100.000 personas $^{20}$. El revuelo armado redundó en que el Plan nunca se pusiera en marcha. Sin embargo, la maquinaria no se paró. Inmediatamente, la Red de Apoyo, en el marco de una suerte de federación de Asociaciones reunidas en lo que se llama el Espace Associatif, se aplica en la elaboración de un "argumentario" (Réseau, 2000) o documento que argumenta, desde el punto de vista religioso, jurídico y sociológico, a favor del cambio en la Mudawana, en el sentido que el Plan propone. A estas alturas, el Plan, que contemplaba medidas que iban más allá de las jurídicas, se asimila únicamente con el cambio jurídico. En este argumentario, la Red busca un argumento "islámico"

\footnotetext{
${ }^{20}$ Según el semanario Demain, la manifestación de Casablanca sirvió, sobre todo, para que los islamistas mostraran "su fuerza tranquila" ("Force tranquille islamiste à Casa", por Hassan B'Nadad. Demain, $\mathrm{n}^{\circ} 2$, 18-24 de marzo de 2000, pp. 8-9)
} 
que sostenga y legitime cada propuesta de cambio que estaba presente en el Plan, y ello da la impresión de que modifica sustancialmente el planteamiento del Plan. A su vez, el Rey Mohamed VI, siguiendo una tradición familiar con relación a la gestión del Estado, forma en marzo de 2001 una Comisión para revisar la Mudawana ${ }^{21}$, y previo a ello, recibe a las asociaciones feministas y a los partidos políticos. No es hasta septiembre de 2003 que la Comisión termina su trabajo y entrega el documento al Rey de Marruecos.

Estos dos hechos, la modificación del tono del argumentario con respecto al del Plan, y la intervención del Rey, que es el Comendador de los creyentes en Marruecos, o jefe religioso, cambian el paisaje. Tienen dos consecuencias inmediatas. Primera, el encapsulamiento de la "cuestión" femenina, como antaño, en el marco de referencia islámico; segunda, la vuelta de los asuntos sociales al control de la monarquía, justamente porque ya no se consideran civiles, sino religiosos. Así, no ha de sorprendernos el contexto en el que fue anunciada, en octubre de 2003, la reforma de la Mudawana. Ésta fue presentada el 10 de octubre en la apertura de curso parlamentario, en Rabat. Esta apertura fue presidida por el Rey Mohamed VI y por el Presidente de la República francesa, Jacques Chirac. Las reformas presentadas recogen las viejas reivindicaciones de las feministas con respecto a los cambios, suavizadas algunas, pero todas y cada una, contextualizadas y justificadas en el marco exclusivo del Corán y de la tradición musulmana en Marruecos ${ }^{22}$. Lo interesante es que parece haber consenso en el seno de todos aquellos que se habían enfrentado casi tres años antes. Para los islamistas de la ORCOFE-PJD y de la Insaf-YAI ${ }^{23}$, no hay esta vez motivo para manifestarse en las calles. Tampoco para las feministas. La actitud de islamistas y feministas arroja alguna incoherencia. A primera vista, no se explica por qué las islamistas aceptan en 2003 unos cambios que no habían aceptado antes, los del Plan del 2000. En este sentido, parece natural la alegría de las feministas, ya que los cambios por los que lucharon tanto, aparentemente ocurrieron. Sin embargo, si nos quedáramos con esto, sería un juicio superficial de la situación.

Para empezar, entre los islamistas hay diferencias en lo que se refiere a la aceptación de estos cambios. Para la ORCOFE - y no hay que olvidar que el PJD ha votado los cambios en el Parlamento, en enero de 2004 - la reforma es

\footnotetext{
${ }^{21}$ Un antiguo dirigente del Istiqlal, Mohamed Bucetta, es nombrado para dirigir esta Comisión. De los veinte miembros, hay cuatro progresistas y doce conservadores (L'Economiste, 11.9.2003).

22 "Yo no puedo, dice el Rey de Marruecos en su discurso de octubre de 2003, en mi calidad de Comendador de los Creyentes, autorizar lo que Dios ha prohibido, ni prohibir lo que el Altísimo ha autorizado" (Le Matin, 11 de octubre de 2003).

${ }^{23}$ En este trabajo, se emplean las siglas del movimiento islamista junto con su ala femenina, cuando la postura o información es de la organización en general, y es asumida por el sector femenino. Por otro lado, cuando se emplea el nombre del movimiento femenino de manera aislada, quiero indicar que es exclusivamente el movimiento femenino quien genera o emite esas opiniones.
} 
una prueba de la "desmarroquinización", inducida por Occidente. Va esta reforma contra la especificidad de Marruecos, y los cambios jurídicos van a redundar en un empeoramiento de las condiciones de vida de las mujeres puesto que contradicen la situación real de Marruecos ${ }^{24}$. Por ejemplo, según una dirigente de la ORCOFE, el aumento de la edad mínima del matrimonio para las chicas marroquíes, puede incidir en la corrupción ${ }^{25}$. Para ella, el objetivo más importante de las chicas marroquíes es el matrimonio, y éste se debe llevar a cabo cuanto antes posible. Éste es el caso de la mayor parte de la población marroquí, chicas pobres, sin medios, sin estudios. Los padres no entenderán que deban rechazar una oferta de matrimonio para su hija adolescente por el hecho de que la ley haya cambiado y ahora sea demasiado joven para casarse. Lo que harán entonces los padres, según afirmaba esta responsable, es falsificar la fecha de nacimiento, para que pueda casarse y culminar cuanto antes lo que es "natural" en la vida.

Y si no comparte los cambios ipor qué acepta la ORCOFE-PJD la reforma? La acepta como parte de su estrategia política frente al Estado. Los atentados del 16 de mayo en Casablanca ${ }^{26}$ tuvieron como consecuencia que los islamistas estuvieran en el punto de mira del Estado. El PJD, entonces, se ve obligado a moderar su discurso y sus actitudes frente a un Estado vigilante. Pero el PJD no puede dejar de tener un discurso para sus bases: éstas esperan que se pronuncie contra toda occidentalización de las costumbres, de ahí el doble discurso.

La Insaf-YAI tiene una opinión diferente respecto al cambio del otoño del $2003^{27}$. Para la organización, los cambios que el Rey de Marruecos anunció, muestran que el futuro va por el camino que ellos habían señalado: que en el Islam está la respuesta. Hace además otra lectura, y es que el cambio siempre es posible, que tiene que ver con la voluntad política. Sin embargo, opina que todo lo ocurrido en octubre de 2003 con respecto a la Mudawana, es un acto de demagogia, porque, si realmente se quiere cambiar algo, sostiene, habría que modificar otros marcos jurídicos que no son exclusivamente el regulador de las relaciones familiares, como por ejemplo el Código Penal, que contiene, dice la portavoz de la organización, muchos aspectos discriminatorios para las mujeres.

${ }^{24}$ Entrevista con Basima Hakaoui, As-sabah, 15 de octubre de 2003, p. 2.

${ }^{25}$ Entrevista con una responsable de ORCOFE, octubre de 2003.

${ }^{26}$ El 16 de mayo de 2003, un grupo de camicaces atentó contra la Casa de España, el Consulado de Bélgica, un hotel de lujo, la Alianza israelí y un cementerio judío en Casablanca, causando 41 muertos. Fueron acusados un grupo de jóvenes que militaban en grupos islamistas radicales, a los que se les asoció con $A l$ Qaeda. La represión contra todos los islamistas fue enorme por parte del poder.

${ }^{27}$ Entrevista con Nadia Yassine, octubre de 2003 y enero de 2004. 
Así, la posición de los dos movimientos de mujeres islamistas frente al cambio responde a un proyecto político amplio: tradicionalista, nacionalista y suavemente anti-imperialista, para la ORCOFE-PJD, pero siempre en línea con la concepción del Estado en Marruecos; rupturista, con un objetivo a medio plazo de "islamizar la modernidad ${ }^{28}$ ", por medio de la educación en el Islam, como corresponde a la Insaf-YAI. $Y$ en este sentido, los ganadores serían los islamistas, pero muy especialmente, el movimiento ganador en esta contienda por el cambio en el Código sería la Insaf-YAI, porque le da legitimidad a su concepción del cambio, y le permite poner a su favor, cuando lo necesite, el potencial musulmán de Marruecos. Ha conseguido traducir el debate sobre el estatuto de las mujeres a los términos religiosos, que son en los que esta organización se mueve bien. Son los suyos. Por esta misma razón, los movimientos feministas son los perdedores: a su favor, el hecho de que los cambios concretos, que ellos planteaban, se hayan por fin llevado a cabo; en su contra, que no han conseguido sacar la cuestión femenina del ámbito religioso, más bien al contrario. No han logrado que se discuta en el ámbito de los derechos humanos y eso les hace dependientes de los representantes de lo religioso en Marruecos.

\section{MODELOS DE MUJER: ¿UN PROYECTO FEMINISTAY OTRO ISLAMISTA?}

Entonces, ¿qué quieren las islamistas para las mujeres? ¿Qué tipo de proyecto plantean? ¿Hay diferencias insalvables con el proyecto de las feministas? ¿Cómo pueden las mujeres trabajar en proyectos que teóricamente pueden perjudicarles?

Los movimientos feministas marroquíes sostienen un feminismo de tipo asimilacionista, o que busca la asimilación, en la terminología de Young (2000). Este planteamiento considera que la emancipación de las mujeres sólo es posible en un proyecto en el que las diferencias entre hombres y mujeres han de ser eliminadas. En ese sentido, las feministas marroquíes apuestan por la desaparición total de las diferencias jurídicas entre hombres y mujeres y por la igualdad en los ámbitos social, político, económico y educativo. Las militantes feministas marroquíes consideran que la cuestión jurídica es fundamental, y que la desigualdad en este ámbito redunda en consecuencias dramáticas para las mujeres, que entroncan con lo que en el lenguaje del desarrollo se llama feminización de la pobreza. Cuando son preguntadas por ello, no reniegan de su herencia musulmana, que consideran su patrimonio cultural, pero la mayor parte de las veces, el argumento musulmán se maneja para hacer frente a las críticas, como estrategia discursiva, como en el caso del argumentario de la Red de apoyo al Plan, antes mencionado.

\footnotetext{
${ }^{28}$ Título de la obra del fundador y líder del movimiento, Abdesalam Yassine, y a la sazón padre de la portavoz del movimiento y responsable de la Insaf, Nadia Yassine.
} 
Los movimientos feministas en Marruecos no difieren esencialmente entre ellos en sus planteamientos, aunque las estrategias para alcanzar los fines sí varíen, sobre todo en lo que tiene que ver con la relación con el Estado.

El movimiento islamista femenino presenta posiciones algo menos homogéneas. Para ORCOFE-PJD, cuyas militantes no se llaman a sí mismas feministas, el modelo de mujer y de familia es compartido con otras corrientes tradicionalistas marroquíes que no se identifican como islamistas ${ }^{29}$. En coherencia con la posición que mantuvieron durante la discusión del Plan, sostienen un modelo de familia asociado a lo que es "tradicional" en Marruecos, y que está representado por la Mudawana de antes del cambio de 2003: necesidad del tutor para que una mujer pueda contraer matrimonio, autorización del matrimonio para las mujeres desde los quince años y mantenimiento de la figura de la poligamia. Más reacios se muestran a contestar afirmativamente a la pregunta sobre la subordinación jurídica de las mujeres dentro del matrimonio. En los medios en árabe ${ }^{30}$ se muestran con menos problemas para defender algunas cuestiones. La poligamia se acepta como parte de lo escrito. La única condición para la poligamia es la que ya figura en el Corán, y es que el esposo pueda tratar a sus esposas de igual manera, sin hacer distingos. Que defienden y aceptan el actual estado de cosas puede verse sobre la base de la asunción de ciertos modelos familiares, como la propia poligamia, en la vida de algún responsable de la organización. Hacen hincapié en el papel de las mujeres como bastión de la familia.

La Insaf-YAI, sin embargo, tiene un planteamiento más original dentro del panorama político marroquí ${ }^{31}$. La primera cosa interesante es que, en su esquema organizativo, la unidad básica es la usra, que corresponde a la familia nuclear, como núcleo básico afectivo ${ }^{32}$. Y ello ya supone un cambio respecto a los islamistas del PJD, que no enfatizan este aspecto. Pero más allá del organigrama, lo cierto es que la propuesta es bastante original con respecto al modelo de familia que tradicionalmente se ha considerado musulmán en Marruecos, y que coincide con la familia extensa. El proceso de nuclearización de la familia, que tuvo lugar entre las clases medias urbanas en el Marruecos de los años ochenta después de la independencia, pero sobre todo, a partir de los años setenta, se considera, en círculos nacionalistas y del propio PJD, como síntoma de la occidentalización, de la desmarroquinización por la que está pasando el país, signo de decadencia.

\footnotetext{
${ }^{29}$ Entrevista con una responsable, octubre de 2003.

${ }^{30}$ Ver la entrevista citada en la nota 24 de este trabajo.

${ }^{31}$ Respecto a esta especificidad, no deja de ser curioso cómo la YAI termina asimilando y poniendo a su favor un comentario que está en los últimos meses presente en los medios españoles. Me refiero al que hace hincapié en la peculiaridad del movimiento. $Y$ uno de los elementos de esta peculiaridad es su posición respecto a la situación de las mujeres.

${ }^{32}$ Tozy (1999) llama la atención sobre esta cuestión.
} 
Sin embargo, las propuestas de la YAI con respecto a los modelos familiares hacen hincapié en la valoración de la pareja, de la unidad conyugal, con una gran importancia de la noción de compañero-compañera. En los relatos que hacen las mujeres de la Insaf de sus historias familiares puede advertirse este proyecto de pareja como ideal romántico, y la lucha política como trasfondo y pilar de tal proyecto ${ }^{33}$.

Respecto a la poligamia, la postura de $A l A d l$ ua-l-Ihsán presenta también cierta originalidad: no la aceptan. La rechazan porque, dicen, las condiciones no son las adecuadas $^{34}$. La poligamia sólo es posible en situaciones especiales, cuando sea realmente necesario (Khalifi, 2003) y cuando se haya instaurado la Charía ${ }^{35}$. Ante los casos concretos de poligamia, los miembros de la Insaf elaboran comentarios negativos, de victimización de las coesposas y de deslegitimación de la práctica como no musulmana, dados los tiempos que corren.

Las mujeres, para la YAI, no son los bastiones exclusivos de la familia, sino que la familia es cosa del marido y de la mujer. Las mujeres de la Insaf no se cansan de repetir que ellas militan y viajan mientras los maridos cuidan a los hijos, y ponen esta situación como muestra de lo que ellas quieren para las mujeres. En el modelo de la YAI, se considera que a las mujeres musulmanas les han sido sustraídos sus derechos - algo que, dicen ellas, las distingue de las feministas occidentales (sic), que partían de una situación en la que no tenían nada, y han ido ganando estos derechos-y se apuesta abiertamente por la ley islámica como el marco donde la recuperación de los derechos es posible. Para la Insaf, las mujeres han de poner a punto la jurisprudencia islámica, algo que siempre han llevado a cabo los hombres.

Con respecto al velo de las mujeres, tanto las militantes de la ORCOFE como las de la Insaf, lo llevan. En principio, están de acuerdo en sostener que es un gesto como creyentes: no descubrir su cabello ante los hombres, excepto si se trata del marido, el hermano, el padre o el hijo, es decir, excepto ante el esposo y los parientes prohibidos (haram) para el matrimonio. Las mujeres de la Insaf, sin embargo, hacen hincapié en el carácter espiritual del velo, y en lo que de

\footnotetext{
${ }^{33}$ Los modelos señalados por estas mujeres recuerdan al representado por la historia que en 1981 dirige W. Beattie, Reds.

${ }^{34}$ Durante el trabajo de campo en una ciudad española, visité con un miembro destacado de la YAI, una institución religiosa musulmana donde trabajaba un hombre marroquí que era bígamo. El esposo bígamo, obligado a justificar su situación, me dio una serie de argumentos bien conocidos para los científicos sociales: necesitaba aquí un hogar, no podía traer a su familia de Marruecos, etc. Para el militante de la YAI, la bigamia en estas condiciones no hacía sino reflejar el desconocimiento que del Islam tenía este trabajador. Comentó que la poligamia era tolerada, pero cuando se dieran las "condiciones adecuadas", es decir, dentro de un futuro Estado islámico.

${ }^{35}$ Con Charia quiero hacer referencia a un ordenamiento jurídico, político y social de base musulmana.
} 
trascendente tiene el gesto de ponérselo ${ }^{36}$. Hay todo un discurso de este último movimiento sobre la vestimenta, particularmente sobre el pañuelo, pero no exclusivamente, que sostiene que la manera de vestirse no es importante. Ello se debe en parte a la necesidad de alejarse de otros movimientos islamistas, sobre todo los de inspiración wahabí, que, según la YAI, son en excesivo rigurosos con la vestimenta, y descuidan otras cosas. Hay miembros que piensan que hay mujeres que, próximas a los planteamientos de la organización, podrían no llevar velo, aunque, como con otras cuestiones, piensan que "todo llegará", una vez en el movimiento. Y la vía para que llegue es la educación en sentido amplio. La Insaf considera básica la educación de las mujeres y su inserción en una profesión. Las militantes cuentan como triunfos la vuelta a los estudios de mujeres que hace veinte años que abandonaron la escuela. La implicación de los maridos con la prole, que permite a las mujeres hacer el trabajo de militancia y llevar una vida profesional, es achacado a la labor educativa de la organización, que ha logrado dar la vuelta a los modelos tradicionales de familia y que busca en las fuentes islámicas la liberación de las mujeres, una suerte de ressourcement ${ }^{37}$, en palabras de la portavoz de la YAI. La ORCOFE-PJD, en cambio, no tiene interés en cambiar estructuralmente la sociedad, mantiene unas posturas acordes, con ciertos matices que se traducen en protestas en los medios, con el establishment, y desde esta perspectiva, intenta paliar las carencias evidentes que presenta la situación de las mujeres en Marruecos.

\section{CONCLUSIONES}

Queda por resolver la cuestión planteada al principio, a propósito de la existencia de un feminismo islamista. Esta pregunta ha sido formulada fundamentalmente para el caso de Irán ${ }^{38}$. De la discusión sobre Irán por parte de las autoras iraníes, exiliadas o no, viene una buena parte de la reflexión que existe sobre esta cues-

\footnotetext{
${ }^{36}$ En un Sboa (fiesta del séptimo día de vida de un bebé) a la que asistí con miembros de la Insaf, una mujer de un barrio contó cómo en un sueño se le había aparecido la esposa del Profeta. Se sorprendió la mujer de que, sin llevar velo, se le apareciera un personaje semejante. Después comenzó a llevar velo. El relato tenía los rasgos de los relatos iniciáticos, que suponían un cambio radical en la vida de las personas, y el comienzo de la pertenencia a una comunidad.

${ }^{37}$ Nadia Yassine. Conferencia pública, Madrid, Círculo de Bellas Artes, 22 de enero de 2004.

${ }^{38}$ Así ha sido hecho por autoras como Mir-Hosseini, (1999), Moghissi (1999), Moghadam (2000), Abou Bakr (2001) o Tohidi (2002: 24). Puesto que se trata de Irán, la pregunta va más allá de dirimir una cuestión terminológica. Se trata de situar a las políticas reformistas que, en la línea de Jatamí, revisan los planteamientos del Islam de la República Islámica con respecto a las mujeres. Esta línea está representada por la revista Zanan (Moghadam, 2000)
} 
tión. Por ello, en este trabajo, es clave esa bibliografía "iraní"39. Y ello, salvando las distancias entre Irán y el mundo arabo-musulmán, distancia enfatizada por los movimientos islamistas marroquíes, en un intento de desmarcarse de un país, Irán, que ellos saben denostado por Occidente y que además es chií.

Lo cierto es que hay división de opiniones respecto a la consideración como feministas de las reivindicaciones sobre el estatuto de las mujeres que parten de los grupos islamistas. Una de las autores que se pronuncia en contra, Moghissi (1999), se pregunta de qué tipo de Islam se está hablando cuando se habla de feminismo islámico (de ahí que se manejen ambiguamente los términos feminismo islamista y feminismo islámico). Para esta autora, lo realmente complicado es imaginar cómo una religión que se apoya sobre la jerarquía de género puede adoptarse como base para la lucha por la igualdad, y por tanto, ser considerada feminismo. Desde este punto, sólo será feminista el proyecto universalista, liberal y asimilacionista, que toma como modelo el movimiento sufragista. Una visión contrapuesta es la que sostiene Abou Bakr (2001), para quien el término islámico, asociado al término feminista, no supone sino admitir que la preocupación sobre roles, derechos y condiciones de las mujeres, hay que ubicarla en un contexto cultural determinado. Tanto el feminismo como el islamismo surgen en contextos culturales concretos, y esta definición de Abou Bakr, tan amplia, que busca llamar feministas a las islamistas, serviría también para calificar de feminismo islámico cualquier tipo de reivindicación que busque mejorar la condición de las mujeres y que surja en un país musulmán, porque es hija de su contexto. La definición de Abou Bakr entronca con una revisión de la definición de feminismo que se ha producido en diferentes ámbitos situados fuera del pensamiento hegemónico occidental. Para Hernández Castillo Salgado (2002), en su interés por hacer un frente común contra el patriarcado, las perspectivas feministas liberales, es decir, las occidentales, no han admitido que el género en culturas no occidentales tiene una serie de especificidades históricas. Para Offen (1991), citado en Nash (s.d.), la extrapolación de estos modelos asimilacionistas ignora otras formas u otras estrategias feministas. Nash insiste en enfrentar la definición dominante de feminismo como pensamiento reivindicativo que toma como base el discurso de la igualdad, para proponer otras definiciones que, sobre bases culturales diversas, reconozcan la jerarquía de género y la diferencia de roles entre hombres y mujeres. En este sentido, Nash se pregunta si el hecho de no tener una base reivindicativa de derechos políticos individuales descarta que estos movimientos sean definidos como feministas.

\footnotetext{
${ }^{39}$ Debo enfatizar este punto dado que dos de los evaluadores de este trabajo se fijaron en este aspecto. Si bien hay escritos sobre islamismo y feminismo que proceden de otras áreas que la iraní, el debate está teniendo lugar en torno a las feministas de ese país, las que viven alli, las reformistas, y las que viven fuera, las exiliadas. De ahí que se use especialmente en este trabajo esta bibliografia.
} 
RIS

REVISTA INTERNACIONAL DE SOCIOLOgIA

№ 39, SEPTIEMBRE-DICIEMBRE, 2004

ÁNGELES RAMÍREZ FERNÁNDEZ

A partir de los datos aportados y de las definiciones, quizás sea el momento de preguntarse si los movimientos islamistas aquí analizados pueden ser o no considerados feministas. Parece claro que la pregunta no cabe en el caso de la ORCOFE, que además, como se ha dicho más arriba, reniega del término y considera a las feministas sus contrarias políticas. Es cierto que esto último puede responder a que el "mercado" de la ORCOFE-PJD está en Marruecos, y tienen que desmarcarse de sus rivales políticos. La ORCOFE no representa una resistencia al sistema ni sostiene ninguna lucha, salvo la de carácter político contra contrincantes políticos de su país, dentro del sistema.

Merece la pena, sin embargo, hacerse la pregunta del feminismo para el caso de la Insaf. En primer lugar, no parece haber duda respecto a su carácter como movimiento de mujeres, adoptando alguna de las caracterizaciones más generales (Molyneux, 2003), si no somos muy estrictos con la cuestión de la autonomía respecto a otros movimientos y si consideramos que lo fundamental es la resistencia frente al sistema dominante y el compromiso de lucha contra la subordinación de género (Wieringa, en Molyneux: 225.) En este sentido, no hay que dejar escapar la posibilidad de la comparación con otros movimientos de mujeres culturalmente lejanos, pero quizás parecidos, como el de las mujeres indígenas mexicanas. Éstas, en el marco del movimiento indígena nacional, denuncian la situación de los pueblos indios en el proyecto nacional, según relata Hernández Castillo Salgado (2002). Pero además, su lucha está dentro del propio movimiento, donde apuestan por acabar con los elementos considerados tradicionales y que ellas consideran que redundan en su opresión y exclusión. La autora, que considera estos movimientos una forma de feminismo, que llama indígena, observa diferencias importantes con el feminismo nacional, en el caso mexicano, de tipo urbano, liberal y no indígena. Para las mujeres indígenas, el feminismo urbano tiene "connotaciones separatistas que se alejan de sus concepciones de la necesidad de una lucha conjunta con sus compañeros indígenas" (p. 3). Esta cuestión es compartida por la Insaf, para quien la complementariedad y la lucha conjunta de hombres y mujeres son elementos clave, y que, de los movimientos feministas, desaprueban esa concepción separatista, que hace que la lucha sea sólo de las mujeres ${ }^{40}$. Las mujeres indígenas, justamente, no se llaman a sí mismas feministas, porque no consideran que compartan las ideas con las feministas.

\footnotetext{
${ }^{40} \mathrm{Las}$ militantes de la YAI me contaron que su organización, cuando se trata de dar, por ejemplo, cursos de alfabetización jurídica, los ofrece conjuntamente a hombres y a mujeres, al contrario de lo que hacen las feministas en sus centros, a los que acuden mujeres. Para la YAI, si sólo se enseña a las mujeres, cuando acaben el curso y vuelvan a casa, se enfrentarán muy probablemente a los maridos. Por ello, la YAI considera que el proceso de educación debe ser para todos, hombres y mujeres, para que ambos estén sensibilizados en el campo de los derechos de las mujeres.
} 
Esto es una diferencia con la Insaf. Hay, y esto sería una segunda cuestión, un manejo de la terminología que no deja de ser interesante. La Insaf, de un tiempo a esta parte, ha adoptado ciertos términos como feminismo islamista, ciudadanía o emancipación. Y ello, a pesar de que, en un segundo momento, la portavoz del movimiento reconoce que el feminismo pertenece a otra tradición que no es propia a Marruecos, y justifica el uso en aras de la "comprensión" por parte del público occidental ${ }^{41}$, sin olvidar que, en este caso, el "mercado" de la YAI está en el exterior, y esto es una manera de protección.

En tercer lugar, hay que señalar que la Insaf habla de la emancipación de las mujeres por medio de la educación. Hemos de hacer una distinción entre el ámbito individual o privado, y el ámbito más amplio, de derechos y deberes en el marco de un hipotético Estado gobernado por el movimiento. En el ámbito privado, la Insaf defiende la educación de las mujeres como una base importante de su modelo. Sostiene también la implicación igualitaria de hombres y mujeres en las obligaciones familiares y profesionales. Sin embargo, su idea sobre el modelo de derechos y deberes de hombres y mujeres como ciudadanos, está aún por definir. No apuestan claramente por un modelo igualitario de derechos y deberes. Mencionan una "complementariedad" en los roles de hombres y mujeres, en vez de la igualdad plena reivindicada por las feministas. Esta complementariedad, que no acaba de ser explicada, tampoco acaba de ser diseñada. Ahora bien, algunos textos de militantes destacadas (Bahraoui, 2003) mencionan esta igualdad de derechos y deberes entre hombres y mujeres que existía en los tiempos del Profeta Mahoma, modelo de sociedad a la que la YAI aspira. A todo ello se suma que su modelo de género sólo será puesto en práctica en un Estado islámico que vendría pacíficamente, después de todo un proceso educativo del pueblo marroquí, en el que el movimiento al completo se encuentra comprometido. Parten de que los derechos y deberes serán asumidos por la comunidad de creyentes como un acto de responsabilidad moral, y que los tribunales apenas serán necesarios (Yassine, 2003), como en una suerte de anarquismo de base espiritual. En estas condiciones, el proyecto femenino se ubica en un marco utópico, y se convierte igualmente en utópico. ¿Qué proyecto es el que supone que la poligamia, por poner un ejemplo, sólo se llevará a cabo en circunstancias excepcionales y que esta excepcionalidad será valorada de manera justa por el marido? La Insaf trabaja con las mujeres en los barrios, las educa, les habla de igualdad y de derechos, y las forma en religión. En el nivel político (de incidencia en las políticas concretas), sin embargo, no es activo, fuera de algunas declaraciones a los medios.

Dado que considera inválido el sistema de partidos actual, no plantea reivindicaciones concretas en el nivel político, porque sería una incoherencia. Es cierto

\footnotetext{
${ }^{41}$ Nadia Yassine. Conferencia pública, Granada, enero de 2004.
} 
RIS

REVISTA INTERNaCIONAL DE SOCIOLOGIA

No 39, SEPTIEMBRE-DICIEMBRE, 2004

ÁNGELES RAMÍREZ FERNÁNDEZ

que hay trabajo con las bases, en los barrios, con las mujeres, pero no hay lucha. En todo caso, hay que decir que la Insaf ha intentado acercarse a las feministas marroquíes, por medio de la participación conjunta en Jornadas sobre cuestiones de género, y ha sido rechazada. En este sentido, la Insaf padece el rechazo también de otros grupos.

Mi tesis es que la posición de la Insaf podría calificarse de feminismo islamista, entendiendo feminismo islamista como un tipo de feminismo étnico. El modelo que representan esas mujeres no corresponde al tradicional y valora la independencia y la acción en las mujeres. En este sentido, sería necesario reconocer que también en la concepción del feminismo liberal hay una base histórica, que no tiene que ser compartida por otros movimientos generados fuera del ámbito del pensamiento occidental. Demandando la igualdad, la Insaf hace hincapié en los valores asociados a lo femenino, en especial la maternidad. Esto en lo que se refiere a la Insaf, que es diferente a la YAI. La Insaf no se concibe sin ser parte de un movimiento político general, de base religiosa, pero de proyección política. Esta falta de autonomía lleva, en definitiva, a considerar la Insaf como parte, y en ocasiones, como brazo estratégico, sobre todo en el ámbito internacional, del movimiento islamista marroquí. La portavoz y fundadora de la Insaf es la hija del líder carismático de la YAI. Ella misma reconoce que hay muchos militantes que no comparten sus ideas. Pero ello no es extraño: la misma labor que dice la Insaf que efectúa dentro de la organización, de sensibilización y educación sobre temas de género, la llevan a cabo las mujeres indígenas mexicanas (Hernández Castillo Salgado, op. cit.)

Pero quizás el problema en cuanto al proyecto feminista no se plantee con la Insaf, sino con la YAI. No sabemos hasta qué punto es excluyente el planteamiento de la Insaf. No hay una respuesta clara a la pregunta de qué ocurriría si, en ese Estado islámico ${ }^{42}$, que dirigiera la YAI, muchas mujeres optaran por no llevar velo o por tener un comportamiento que no entre en esa construcción de género del movimiento. La respuesta de la Insaf a esta cuestión denota la importancia dada a la educación por la organización: no sería posible aquella situación, porque con la educación, "todo llegaráa3". Y la pregunta que queda en la recámara es: ¿qué ocurre si no llega, y hay muchas mujeres que no comparten esos valores del grupo? ¿Se las obligaría? Y aquí el debate volvería a otro lugar natural: al conflicto entre los derechos individuales y colectivos, conflicto que, desde los movimientos de resistencia no occidentales, se considera de naturaleza occidental.

\footnotetext{
${ }^{42}$ Estado islámico es una frase que la Insaf parece considerar tabú, probablemente porque, tanto en Marruecos como fuera de Marruecos, está demasiado asociado a un Irán siniestro y represor.

${ }^{43}$ No deja de ser curioso el que el movimiento piense que la fe pueda ser inducida.
} 
Por último, queda otra cuestión más práctica, ya planteada al principio, y es la de la polarización existente en Marruecos entre los dos movimientos, el feminista y el islamista, respecto a la situación de las mujeres. Para las feministas marroquíes es fundamental el apoyo del feminismo transnacional, para cobrar fuerza y para disponer de medios que les permitan seguir trabajando. Desde esta perspectiva, para este feminismo transnacional sería impensable que trabajaran con las islamistas. Para la Insaf, sin embargo, sería muy importante atraer a las feministas, lo cual les daría también legitimidad en el exterior ${ }^{44}$. Los movimientos, además de su ideología, tienen su público en Marruecos. Si la Insaf puede acercarse al movimiento feminista sin que su base de apoyos sea perjudicada es porque, primero, no se traduce inmediatamente en votos (la YAI no es un partido político), y segundo, no es la YAI la que se acerca a las feministas, sino un sector de la YAI, que aunque hasta el momento no se haya dado el caso, podría ser desautorizado en cualquier momento ${ }^{45}$.

En este sentido, mi conclusión es que la polarización entre militantes islamistas y militantes feministas ha de ser explicada en términos de intereses políticos y estratégicos de los grupos, más que recurriendo a posturas ideológicas irreconciliables sobre el papel de las mujeres en la sociedad. En definitiva, con esta investigación pretendo indagar en el islamismo como cotidiano femenino en el contexto marroquí, más allá de planteamientos culturalistas que, sospecho, serán cada vez más frecuentes. Creo que es fundamental la etnografía para conocer y hacer conocer estos grupos. $Y$ en estos tiempos, la investigación es, más que nunca, un arma política, que hemos de usar para evitar que la tragedia del 11 de marzo desate comportamientos anti-marroquíes y anti-musulmanes.

\section{REFERENCIAS BIBLIOGRÁFICAS}

ABOU-BAKR, O. (2001), "Islamic Feminism? What's in a name? Preliminary Reflections", News Vol. XV (4)/ XVI, pp. 1-6.

ABU-LUGHOD, L. (2002), "Do Muslim Women Really Need Saving? Anthropological Reflections on Cultural Relativism and Its Others", American Anthropologist, n 104 (3) (September), pp. 783-790.

AHMED, L. (1992), Women and Gender in Islam, New Haven y Londres, Yale University Press.

\footnotetext{
${ }^{44}$ Especialmente interesante son las menciones públicas a Fatima Mernissi, una de las pioneras del movimiento feminista en Marruecos, y de la investigación feminista desde la sociología. Mencionada en las conferencias de Nadia Yassine en Madrid y Granada, en enero de 2004, y en Bahraoui (2003)

${ }^{45}$ No así para la ORCOFE-PJD, para quien el contacto con las feministas perjudicaría presumiblemente el volumen de votos de la segunda parte del tandem, el PJD.
} 
RIS

REVISTA INTERNACIONAL DE SOCIOLOGTA

No 39, SEPTIEMBRE-DICIEMBRE, 2004

BAHRAOUI, G. (2003), “Les femmes modèlent l'avenir”, Conferencia pública impartida el 25 de mayo de 2003 en París (mairie de Poissy).

DAOUD, Z. (1994), Feminisme et politique au Maghreb, Casablanca, Eddif.

DEL OLMO, A. (2000), La nueva configuración del espectro asociativo femenino en Marruecos: historia del Plan de Integración de las Mujeres en el Desarrollo, Tesina de Master en Género y Desarrollo, Madrid, 2000 (inédito).

ELORZA, A. (2002), "Islam: pluralidad cultural y terrorismo", Claves de Razón Práctica, n 119, pp. 8-17.

HERNÁNDEZ-CASTILLO SALGADO,A. (2000), "Distintas maneras de ser mujer: ¿Ante la construcción de un nuevo feminismo indígena?", Rima (Red Informativa de mujeres de Argentina) Fecha de publicación en RIMAweb, agosto 2002 (URL: http:/www.rimaweb.com.ar/feminismos/ revisión_indígena.html).

HERNÁNDEZ RAMOS, P. (2003), "Elecciones municipales en Marruecos. El alcance del voto islamista", Análisis del Real Instituto Elcano, 3/11/2003.

KHALIFI, M. (2003), "La femme dans le projet de $\mathrm{Al}$ Adl ua al Ihssane en quelques questions", Documento fotocopiado para uso interno.

LINDISFARNE, N. (2003), "Starting from Below. Fieldwork, Gender and Imperialism Now", Critique of Anthropology, $n^{\circ} 22$ (4), pp. 403-422.

LÓPEZ, B. y A. RAMÍREZ (2002), "Felipe Ovilo: testigo del cambio en el Marruecos del siglo XIX", en A. Ramírez y B. López, Antropología y antropólogos en Marruecos. Homenaje a David M Hart, Barcelona, Bellaterra, pp. 157-171.

LÓPEZ, B. e I. MORÉ (2004), "Harragas e islamistas: las opciones de los nuevos magrebíes. La otra cara de las migraciones marroquies", Cuadernos de la Escuela Diplomática (en prensa).

MIR-HOSSEINI, Z. (1999), Islam and Gender: The Religious Debate in Contemporary Iran, Princeton, Princeton University Press.

MATEO DIESTE, J. L. (2002), "La paraetnografia militar colonial: poder y sistemas de clasificación social", en Ramírez y López, Antropología y antropólogos en Marruecos. Homenaje a David M. Hart, Barcelona, Bellaterra, pp: 113-135.

MOGHADAM, V. (2000), "Islamic Feminisms and Its Discontents", Iran Bulletin, April 2000.

(2001) "Afghan Women and Transnational Feminism", Mews Review Articles (xvi), pp. 3-4.

MOGHISSI, H. (1999), Feminism and Islamic Fundamentalism. The limits of Postmodern Analysis, Londres, Zed Books.

MOLYNEUX, M. (2003), Movimientos de mujeres en América Latina, Madrid, Cátedra.

32 
NASH, M. (S.D.), “El aprendizaje del feminismo histórico en España”, Mujeres en Red.

OFFEN, K. (1991), "Definir el feminismo: un análisis histórico comparativo", Historia Social, $\mathrm{n}^{\circ}$ 9, pp. 103-135.

RÉSEAU DE SOUTIEN AU PLAN D'ACTION NATIONAL POUR L'INTÉGRATION (2000), Légitimité des mesures proposées par le Plan National d'Intégration de la Femme au Développemen. Argumentaire religieux, juridique et sociologique en faveur du Plan National d'Action pour l'Integration de la femme au développement, Espace Associatif.

SÉCRETARIAT D'ÊTAT CHARGÉ DE LA PROTECTION SOCIALE, DE LA FAMILLE ET DE L'ENFANCE ET BANQUE MONDIALE, (1999), Plan d'Action pour l'Intégration des Femmes au Développement, Document provisoire, Janvier.

TOHIDI, N. (2002), "Islamic Feminism: Peril and Promises", MEWS, vol. XVI (314), pp. 13-17.

TOZY, M. (1999), Monarchie et Islam Politique au Maroc., París, Presses de Sciences Po.

YOUNG, I.M. (2000), La justicia y la politica de la diferencia, Madrid, Cátedra. 